\title{
Afastando fantasmas da história recente...
}

\author{
Sandra Ramalho e Oliveira
}

Nos currículos de formação dos professores de arte existe um espaço destinado à história do ensino de arte no Brasil; para fundamentar a abordagem deste assunto, subsidiamo-nos em uns poucos autores, com destaque para Ana Mae Barbosa, na sua História da Arte-Educação. Mas, ao longo da existência desses mesmos cursos de formação, e em decorrência da atuação de seus egressos, fomos construindo uma nova etapa dessa história. Por mais paradoxal que pareça a expressão "história contemporânea", é isso que aqui tentamos alinhavar: aspectos relacionados à história recente do ensino de arte em nossa realidade brasileira, através desse ângulo particular, de sul do Brasil. Este texto apresenta uma revisão dos principais problemas encontrados na realidade educacional, sendo que um dos referenciais é uma pesquisa de campo da década de noventa.

Desde o advento da Lei 5.692/71, toda uma nova história do ensino da arte no Brasil foi construída. Não se trata da história do ensino da arte contemporânea, mas a história contemporânea (embora sempre um paradoxo, esta expressão) do ensino da arte. Ao longo desse tempo, aconteceram os "erros e acertos" já sabidos; alguns desdobramentos dessas questões foram superados; outras deixaram suas marcas; mas muitas heranças ainda permanecem entre nós. Assim, já temos, nesta nova história, muito para refletir.

\section{Em defesa da leitura}

Vários são os pontos que podem ser levantados para discussão e entre eles percebem-se 
íntimas relações. 0 primeiro item a ser considerado é a suposta dicotomia que muitos estabeleciam entre o fazer e o fruir, o criar e o apreciar, o expressar e o compreender, ou seja, entre produção e leitura da obra de arte. Um dos motivos que contribuíam para a visão bipolarizada é o fato de que as experiências de ensino de arte foram centradas, preponderantemente, na produção de trabalhos artísticos. Ficou em segundo plano a leitura, tida como procedimento ligado à teoria; para muitos professores, aula de arte era para fazer arte somente, mesmo que de maneira intuitiva, e este conceito foi, inevitavelmente, repassado ao aluno.

Outro aspecto a considerar é que, no contexto escolar, é preciso atribuir notas ou conceitos e parece que são consideradas mais idôneas as avaliações sobre conteúdos exclusivamente teóricos. A este respeito, assim se pronunciam Ramalho e Oliveira et al., com base em pesquisa de campo realizada na Grande Florianópolis:

a maioria das aulas são praticadas (fazer artístico); a teoria é tida como 'maçante', pois está ligada a métodos de ensino por vezes ultrapassados, cópias exaustivas de textos, ditados de conteúdos (prática da escola tradicional), leitura de apostilas e livros didáticos que não fazem relação com exemplos do cotidiano. A aversão à teoria está também ligada à relação que os alunos fazem entre o conteúdo teórico e as provas (1994, p.34),

Constatadas as dificuldades de alguns professores com relação a conteúdos, métodos de ensino e avaliação, não era de se estranhar sua opção pelo chamado fazer artístico, como se a leitura não fosse também um fazer. Assim limitados, os professores não percebiam que criar e fruir são processos que devem estar presentes no ensino de arte dentro de uma concepção dialética e não 
dicotômica. Ambos estão apoiados em teorias e ambos demandam uma prática. Consagrava-se a idéia de que a prática e o fazer artístico, dispensam a teoria, e teoria passava a ser entendida como um estudo desnecessário e alheio à própria produção do aluno.

Essa dicotomia, em sala de aula, poderia ser percebida pelos alunos como uma situação maniqueísta onde o fazer artístico era bom, divertido, dispensava maiores estudos. Para eles, a leitura da obra poderia parecer pouco agradável porque demandava o conhecimento de teorias, precisava de estudos, já que muitos percebiam estudos como a memorização de dados e não como compreensão de processos. Assim eram feitas duas equivocadas correlações: uma entre produção e prazer e outra, entre leitura e desprazer.

Era preciso questionar essa prática, esse método de ensino e essa produção artística; por que quase todo trabalho do aluno acabava sendo bem aceito pelos professores? Que critérios eram utilizados para avaliação? É porque os trabalhos obedeciam à norma estética? Ou porque violavam a norma? Ou, entre eles, quais quebravam a norma? Que norma? Existem normas, em arte?

Outra motivação para os professores adotarem exclusivamente a produção, nas aulas de arte, decorria do fato de a prática oferecer produtos concretos. Essa produção, uma vez criativa, uma vez meio de comunicação, uma vez expressão do saber vivido e adquirido associado à imaginação dos alunos, é ilimitada. Formas e cores, sons e ritmos, gestos e movimento podem ser, por si sós, mecanismos de deflagração de resultados que independem da ação do professor. Mas são resultados concretos a serem apresentados para os pais e à direção da escola. Desta maneira, bons trabalhos de alunos podem mascarar uma atuação 
medíocre do professor, o qual também pode esconder-se atrás de resultados até certo ponto casuais ${ }^{1}$.

Assim, nas aulas de arte, fazia-se muito (e era o aluno quem fazia, e isso levava tempo...) e apreciava-se pouco. E o que fazia o professor enquanto o aluno fazia arte?

0 que seria mais fácil (para o professor): mostrar como se conseguia determinado efeito, através de uma técnica, e conceder tempo para a classe produzir um trabalho, ou fazer, em conjunto com os alunos, a leitura de uma obra?

À opção pela criação em detrimento da apreciação nas aulas de arte pode somar-se outra causa: o fato de que a leitura de obras de arte exige maior envolvimento dos professores, já que cada obra é uma obra, além de maiores níveis de conhecimento sobre arte. E havia a carência de bibliografia... e de tempo para a preparação de aulas...

Em defesa de atividades exclusivamente práticas acorriam os que as justificam dizendo que em aulas de arte tinha que haver arte, tida como sinônimo de criação. Assim fugia da sala de aula a leitura de imagens. Acaso uma leitura adequada, com base em parâmetros estéticos não é uma tradução criativa, uma recriação? O ler não é somente um mero, superficial e mecânico ler. Uma leitura criativa não é, como no código verbal, uma leitura de notícias em um jornal; seria um ler poesia, literatura. Uma leitura criativa não é como assistir um filme preocupado apenas com o enredo ou com o happy end, mas sim percebendo e dando

1 Dados sobre a presença do acaso em processos de criação artística podem ser encontrados na obra de F. Ostrower, Acasos e Criação Artística. Rio de Janeiro, Campus, 1990. 
sentido a todos os elementos e procedimentos relacionais geradores de significado, que participam do conjunto da obra.

Criar significa elaboração, mas sempre deve ter como base determinados princípios; apreciar, por sua vez, deveria ser também elaboração, a partir exatamente dos mesmos parâmetros. Em ambos os processos, devem estar presentes o conhecimento estético, a compreensão do respectivo código e de seus mecanismos; somente reconhecer uma obra, relacionando-a a determinado estilo, escola ou autor não é, verdadeiramente, conhecê-la; apreciação de um texto estético é também criação, uma vez que leitura não é a mera aceitação de uma proposição estética. É preciso penetrá-la, percorrendo os caminhos deixados nela por seu autor, percebendo as relações possíveis entre todos os elementos, criando renovados significados, isto é, atualizando os sentidos da obra.

Quando se analisa um texto estético, deparase com um conjunto de formas; em seguida, a imagem pode ser decomposta, dando origem a outras formas, às vezes escondidas no todo da obra; o olhar (ou o ouvido) compara, destaca, suprime, re-arranja figuras; e neste processo de desconstrução e re-construção, o sujeito leitor é quem, à sua maneira, traduz a imagem. Quem lê recria a imagem pois, como o artista, também produz significados.

Não tem sentido essa dicotomia entre produzir e apreciar, pois ambas são atividades que, inicialmente, demandam conhecimentos estéticos; em segundo lugar, elas exigem a mesma elaboração mental, acerca de idênticos elementos e processos, pois tanto uma quanto a outra envolvem procedimentos criativos e produtores de significados. 
Por sua vez, o fazer pode consistir em um mecanismo para melhor perceber, para melhor conhecer a arte. $\mathrm{E}$ isto adquire importância porque existe uma relação dialética entre o perceber e o conhecer: percebe-se o que se conhece e quanto mais se percebe, mais se conhece. Não é demais lembrar que a leitura de trabalhos dos mais diversos produtores é um referencial indispensável para todo aquele que se propõe a criar um texto estético.

É provável que a leitura seja feita de maneira até mais completa, ou com maior facilidade se se tiver familiaridade com o processo do fazer, pois a vivência da construção pode auxiliar na compreensão dos efeitos da obra pronta, ainda que o texto encerre em si todo o seu significado. Mas esse fazer, em nível escolar, não deve ser um fazer do tipo profissional, mas apenas exercícios de interação com e de manipulação de meios e processos de expressão e comunicação.

A busca de um padrão de produção verdadeiramente artístico na escola, a seleção de trabalhos, a avaliação simplista do tipo bom / ruim e os famigerados concursos, acabam reforçando apenas as qualidades expressivas de uma minoria, de origem, às vezes, intuitiva ou técnica, derivada de maiores oportunidades para o desenvolvimento da motricidade. Atitudes como essas acabam afastando da arte aqueles que justamente mais precisam de estímulos para dela se aproximar. Não "tendo jeito" para arte, acabam, para sempre, excluídos da possibilidade de acesso aos conhecimentos contidos no acervo e na produção estética, já que foram julgados incapazes nesse campo.

Diante de todas estas ponderações, considera-se importante levar em consideração propostas que integrem - no criar, no fruir, no 
recriar, no perceber, no conhecer, no compreender, no traduzir - os elementos constitutivos dos códigos estéticos, bem como as regras de combinação que articulam os elementos e os significados que deles emergem.

\section{O tempo da arte}

Ainda analisando a produção, ou o "fazer artístico" em sala de aula, levanta-se outro aspecto: a questão do tempo necessário para a aula de arte; muitos advogaram um tempo indeterminado, qual fora um ateliê, o que dava a impressão da expectativa de um desempenho do tipo profissional.

Sabe-se que aprender a tocar, de maneira razoável, um instrumento musical, demanda muito tempo; performances dramáticas ou uma produção aceitável em artes plásticas também precisam de tempo. Por isso, o tempo destinado às aulas de arte centradas no fazer parecia sempre insuficiente. Com tempo limitado, o aluno acabava saindo da escola com um referencial de qualidade duvidosa em música, deixando empoeirada sua flauta doce no fundo do armário ou vendendo como objeto de segunda mão o seu instrumento para outro colega mais jovem que, como ele, começava um processo condenado à incompletude. Na mesma poeira, provavelmente, também ficaram aqueles desenhos "do tempo de escola". Pergunta-se, então: para que teriam servido?

Vygotsky ao buscar analogias entre códigos e tendo como foco o verbal traz da música um exemplo para mostrar a diferença entre um aprendizado de habilidades, mecânico, e uma penetração de fato na natureza de um sistema de códigos: "o aluno desenvolve a destreza de seus dedos e aprende quais teclas deve tocar ao mesmo tempo que lê a partitura; no entanto, ele não está, 
de forma nenhuma, envolvido na essência da própria música" (1991, p.119-20).

Por outro lado, com relação às artes visuais, Lanier (1984, p.7) afirmando que décadas de aulas de arte em ateliê não produziram, na sua realidade norte-americana, uma "população massivamente afeita às Belas Artes”, propõe que se questione o centramento das aulas de arte na produção artística.

Mesmo admitindo ter sido veementemente criticado por colegas, Lanier defende a idéia de que não é a produção a única fonte de entendimento de um determinado código, desafiando, em seguida, o leitor a refletir se the foi necessário escrever, produzir, dirigir ou atuar em um filme ou em uma peça teatral para poder compreendê-los. E pergunta: "é necessário que joguemos futebol para podermos entendê-lo ou desfrutá-lo?" (Ibid., 1984, p.7).

Concorda-se com a tese de Lanier (1984), especialmente pelo fato de ele ter o cuidado de fazer a ressalva, ou seja, de deixar explícito que a produção não é a única fonte. Produção é, sem dúvida, uma das fontes para o entendimento da arte. Porém, não é a única. Conforme a proposta educacional vai haver um modo de conduzir os trabalhos; o foco pode estar na produção ou pode estar na leitura da imagem. Ambas podem ser formas de acesso à arte. Mas neste estudo, pretende-se recuperar a importância da leitura, já que o fazer não precisa de mais defensores. E talvez, para entender e desfrutar, conceitos propostos por Lanier, sejam resultados que não demandem tanto tempo...

\section{Arte, para quê (ainda!)?}

Voltando-se para o foco do ponto em discussão, percebe-se que, durante esses últimos trinta anos, e mesmo hoje, infelizmente, ainda se discute a função 
da arte na escola. Alguns ainda falam em despertar talentos ${ }^{2}$. E para que terá servido o tempo dispensado pelos destituídos de dons?

$\mathrm{Na}$ realidade, o currículo escolar deve pretender preparar os alunos para a vida, e não para serem artistas, assim como se ensina matemática para a vida e não para serem matemáticos e a leitura e a escrita da língua materna, do mesmo modo, é ensinada para ser usada nas mais diferentes situações de comunicação e não, especificamente, para que os alunos se tornem escritores ou poetas.

Ainda assim, cumpre acrescentar: escritores e poetas são os que mais profundamente conhecem a língua, através da compreensão do seu funcionamento, o que pode ser melhor observado a partir da leitura. Quanto mais familiarizados estiverem os alunos com os códigos estéticos, tanto melhor será sua compreensão dos processos, seja ele o da produção ou da leitura da imagem.

A aula de Arte acontece em níveis de ensino não profissionalizantes. Dos contingentes da população em idade escolar, alguns apenas serão artistas. Por outro lado, o acesso ao conhecimento e aos benefícios culturais expressos em forma de arte, através de sua tradução e compreensão, deveria ser garantido a todos os cidadãos. A grande maioria dos professores de arte concorda com este princípio; contudo, na prática, não se verifica a coerência de todos com seu próprio discurso.

Talvez este problema tenha origem na própria formação dos professores disponíveis quando da 
introdução da disciplina Educação Artística nos currículos. Em grande parte, eram oriundos de academias e conservatórios. Os mais jovens, de bacharelados em arte, às vezes distanciados da realidade e das necessidades do aluno em fase escolar; tendo sido preparados para serem artistas, não sabiam fazer outra coisa que não fosse reproduzir o que thes havia sido ensinado. Como pode ser observado, a situação explica a incoerência entre o discurso sobre não ser objetivo preparar artistas e a prática adotada e também a cobrança sistemática de uma produção artística de professores de arte.

\section{"Quem sabe faz, quem não sabe ensina"?}

O campo da arte é composto, igualmente, pela produção de artistas que, por circunstâncias diversas, jamais escreveram uma linha sobre o seu fazer, por elaborações de teóricos que jamais pegaram em um pincel ou subiram em um palco, bem como - e aí os exemplos são mais raros - de artistas que conseguiram teorizar sobre sua própria produção.

Mas o valor de Da Vinci não está no fato de ele ter também escrito; não é porque Klee, Kandinsky, Matisse ou Malevitch, Villa-Lobos, Jorge Luis Borges ou Glauber Rocha verbalizaram reflexões sobre sua produção que sua obra se torna superior a de tantos que não o fizeram; e também este fato não os torna mais importantes para a humanidade do que outros produtores de arte. Por outro lado, Kant, ao que se sabe, não foi artista; nem Hegel ou Croce; mas todos têm uma participação inegável no que se refere às questões relativas à arte e à estética.

Uma característica das teorias da arte é que, por serem basilares, suas proposições podem ser 
aplicadas a diferentes formas de expressão; elas tratam da essência da arte. A partir da modernidade, diversos teóricos têm demonstrado essa característica, ao discutirem princípios estéticos aplicados simultaneamente a diferentes códigos artísticos. É o caso de Roland Barthes, Abraham Moles, Suzanne Langer, Étienne Souriau, Jan Mukarovský ou Michel Foucault, para citar alguns dos teóricos contemporâneos.

Assim, a polêmica questão acerca da impossibilidade de o professor de arte poder ser habilitado para transitar entre diversos códigos parece ser um subproduto do centramento ou da exclusividade do fazer em sala de aula, derivado da preparação de professores para uma área específica, pessoas às vezes mais preocupadas com as técnicas que thes tomaram tantos anos para aprender, do que com as questões essenciais da estética.

Acredita-se que contribua para esta polêmica, na prática e diante dessas circunstâncias, um outro problema, de ordem política. Um professor que se sinta à vontade no contexto da Arte, considerado o campo dos diversos códigos, será uma ameaça à reserva de mercado, aos feudos das especialidades, podendo ser visto como um invasor de áreas.

Esta questão é bastante atual, mas numa visada histórica do ensino de arte como obrigatório, nas escolas brasileiras, observar-se-á que a exclusividade de área não foi a concepção originalmente adotada, há mais de trinta anos: conteúdos abrangentes, abordando diversos códigos. O problema é que não foi prevista qualquer espécie de articulação entre eles. 


\section{Da polivalência à transdisciplinaridade}

Inicialmente, por força de determinações legais, o currículo das escolas e, conseqüentemente, o adotado para a preparação de professores de Educação Artística levava-os à polivalência, ou seja, a aprender (leia-se: geralmente praticar) alguma coisa sobre artes plásticas, teatro, música, história da arte, folclore, desenho geométrico. Não havia uma preocupação maior com a compreensão do que era produzido ou apreciado, com o conhecimento dos elementos estéticos em si e com as possibilidades de estruturação desses elementos, de acordo com as regras dos respectivos códigos, o que impossibilitava qualquer articulação entre os conhecimentos de uma e outra área. Restava, aos professores assim preparados, a reprodução superficial e fragmentada do que havia sido vivenciado como alunos na sua própria prática profissional.

Por um lado, os bacharéis e artistas aproveitados para ministrar a nova disciplina que surgia, no currículo das escolas, não tinham a denominada formação pedagógica e dirigiam o trabalho de acordo com seus conhecimentos pessoais e sua própria concepção de ensino de arte. Por outro, os cursos universitários, criados para suprir a demanda de profissionais em função da inovação no ensino fundamental e médio conceberam seus currículos como um conjunto diversificado - mas não articulado - de conteúdos e práticas artísticas.

Esta nova categoria de profissionais, habilitados legalmente para atuar nas escolas, acabou se perdendo na diversidade desarticulada da sua preparação e, até mesmo, muitas vezes ficando aquém, no que toca à consistência de conhecimentos, se comparados com os bacharéis 
que atuavam a título precário. Aqui nós, professores das agências formadores desses professores, temos que botar a mão na consciência.

Foi a esta falta de consistência que se atribuiu, nos primeiros anos, a ineficácia do ensino de arte nas escolas, uma vez que se entendia que a pulverização da arte em diversos códigos era a responsável pelo fato de os alunos não conhecerem $a$ arte o suficiente para por ela se interessar.

A respeito desta situação inicial, baseada em pesquisas realizadas pela Universidade de São Paulo (USP), nos diz Barbosa (1984, p.23-4): "durante os primeiros sete anos, a educação artística foi um caos, uma inutilidade, uma excrescência no currículo, com professores despreparados, deslocados e menosprezados pelo sistema escolar". A própria autora aponta para a solução da interdisciplinaridade.

Rejeitando, por completo, a polivalência, processaram-se alterações curriculares nos cursos de licenciatura em Educação Artística, implantando-se as habilitações específicas - artes plásticas, artes cênicas, música, dança e desenho, ampliando-se o número de disciplinas, aprofundando-se os conteúdos relacionados a cada habilitação e diminuindo-se as disciplinas relacionadas aos códigos artísticos "estranhos" à respectiva área.

Esperava-se que o banimento do ecletismo justaposto de "linguagens" e sua gradativa substituição pelas teorias e práticas específicas e inerentes a cada habilitação imprimissem a qualidade necessária aos professores de arte, melhorando, conseqüentemente, a situação do seu ensino nas escolas do país.

Então, verificou-se um grave problema, pois as escolas não tinham - e ainda não têm - condições 
para manter diversos professores de arte com habilitação específica nos diferentes códigos, que pudessem vir a construir uma proposta educacional interdisciplinar. Mesmo que vivenciando melhores aulas, ministradas por um professor especialista, geralmente os alunos eram iniciados no estudo de apenas um sistema, o da habilitação específica do professor que sua escola contratou.

Afastada a ineficácia decorrente da polivalência, surge o fenômeno da especialidade. Ainda que Barbosa (1984, p.25) tenha insistido na necessidade de

o professor de arte romper com a generalidade amorfa da polivalência e tentar um trabalho aprofundado em uma das artes sem cair na compartimentação, sem deixar de ter como referência outras linguagens artísticas, na busca de uma organização integradora do conhecimento,

0 que se observava, na realidade, eram professores comodamente protegidos atrás do escudo da não-polivalência, defendendo-se dos desafios decorrentes do estabelecimento de relações não só com outras áreas de conhecimento, como, até mesmo, com os demais códigos artísticos. Isto porque eles também eram vítimas da cegueira da qual nos fala Plaza:

"num arco-íris sincrônico da história, desde Altamira aos meios eletrônicos, segundo a óptica da sensibilidade, podemos ver aparecerem os aspectos de inter-relação sinestésica para os quais, infelizmente, a especialização dos sentidos em categorias artísticas bem demarcadas, de certo modo, nos cegou" (1987, p.11).

Pergunta-se: é possível transpor ou apagar as rígidas demarcações? É possível se "pensar transdisciplinarmente"? Sabe-se que existem 
elementos e procedimentos assemelhados entre os diversos códigos estéticos: na textualidade musical, encontram-se procedimentos semelhantes aos encontrados na textualidade cênica e nesta, elementos análogos aos do sistema visual. Trata-se de uma visão abrangente, intertextual e, sobretudo, uma tentativa de somar o aprofundamento que é esperado da especialidade à abrangência que, na equivocada e fragmentada forma polivalente, não foi possível trabalhar. Mas estariam os professores preparados para tal?

Retoma-se uma citação anterior de Barbosa (1984, p.7). Se é levantada a hipótese de que o aluno poderia, ele mesmo, estabelecer "conexões e relacionamentos diversificados e pessoais" entre "linguagens", aqui se quer refletir sobre esta possibilidade de o aluno ser sujeito desse processo, bem como sobre a possibilidade de o professor ter condições de conduzir o aluno a fazê-lo.

\section{Espontaneísmo}

Outra questão relacionada ao ensino de arte realizado na história recente em nossas escolas diz respeito aos métodos utilizados. Educadores, em qualquer área, abominam o que chamam de receitas, ou seja, os modelos prontos, prescritos por alguém que, com autoridade professoral, apresenta sua proposta como se ela fosse válida para qualquer tempo e lugar. Concorda-se com esta posição, uma vez que cada realidade tem suas especificidades e cada educador, diante da sua realidade, deve ser sempre o sujeito que produz a sua prática e reflete sobre ela; experiências de outros contextos, sistematizadas em teorias ou não, podem e devem servir como parâmetro, mas o contexto dos seus alunos é decisivo, assim como sua responsabilidade sobre ele é intransferivel.

Quando se trata do ensino de arte, tem sido freqüente observar um outro extremo, tão ou mais 
pernicioso do que um método rígido, um modelo inflexível. A rejeição a modelos pré-determinados têm levado os professores de Arte a uma pretensa criatividade, muitas vezes irrefletida. 0 mesmo laissez-faire condenado pelos professores, enquanto técnica de ensino de arte é por eles adotado, entre outras alternativas metodológicas ${ }^{3}$, como se fosse uma técnica de planejamento do ensino. Não era difícil encontrar, durante os primeiros anos de ensino de arte obrigatório, uma espécie de permissividade educacional, onde toda experimentação e qualquer improvisação eram válidas, mesmo que destituídas de qualquer embasamento teórico.

Acabava acontecendo na escola, realidades de dois pólos extremos: ou a adoção de um método rígido, até mesmo de cadernos de exercícios impressos, ou a improvisação, ambos situações encontradas por Ramalho e Oliveira et al. (1994, p.34); segundo constataram as pesquisadoras,

os professores também têm aversão à teoria, lêem pouco, possuem pequeno referencial teórico e utilizam-se amplamente de livros didáticos. (...) Os planejamentos não são executados rigidamente, predomina o improviso na preparação das aulas diárias.

Nesta pesquisa, como em outras investigações e publicações da área, percebe-se que o destaque foi dado mais aos problemas do que às experiências bem sucedidas. Tendo feito parte do grupo de uma das pesquisas aqui usadas como subsídio, sentimo-nos à vontade para assumir essa revisão. Mas o que motivava esta espécie de "index" era antes evitar os "erros" tradicionais do

3 Esta constatação é resultante dos resultados das pesquisas "O Empirismo Metodológico no Cotidiano do Professor de Educação Artística" (Ramalho e Oliveira et al., 1994) e "O Ensino de Educação Artística na Grande Florianópolis" (Albuquerque et al., 1993). 
que a "caça às bruxas". Mesmo que não fossem bem vistas as "receitas", talvez tivesse sido mais eficaz mostrar trabalhos bem sucedidos do que situações questionáveis, muitas até apresentadas como ridículas.

\section{Enfim...}

Estas são algumas palavras sobre uma história vivida e algumas de suas principais questões; tratase de uma história que precisa ser escrita. Falar em "erros e acertos" seria reforçar o maniqueísmo. Mas o que é certo mesmo é que tudo mudou, e mudou para melhor.

Não se pode omitir a existência de trabalhos relevantes, que adquiriram credibilidade não só pela forma como foram construídos, mas também porque foram adequadamente submetidos à comunidade científico-educacional.

Nesta perspectiva, ninguém pode esquecer o valor inestimável do trabalho de Ana Mae Barbosa, da sua busca pessoal de fundamentos, de nos ensinar a todos que fundamentos devem ser buscados e, sobretudo, pela conquista do espaço político hoje legado a todos nós, "professores de arte do Brasil".

Por último, ainda se quer lavrar um protesto quanto à perda de tantas outras reflexões e metodologias de ensino de arte, uns até apresentados em eventos e outros restritos às escolas, os quais não conseguem espaço editorial para serem disseminados através de publicação. São os produtos dos heróis anônimos que não perdem o entusiasmo, malgrado as dificuldades tão conhecidas.

Assim, o que se lamenta é que, durante esses mais de trinta anos de ensino de arte obrigatório, 
muitas experiências importantes não tenham sido divulgadas de maneira que pudessem ser suficientemente conhecidas e discutidas. Transformaram-se em trabalhos solitários, dependentes dos professores que os conceberam, submetidos apenas às suas auto-avaliações e, freqüentemente, destituídos de qualquer possibilidade de continuidade.

Outro dia, em uma banca de mestrado, soube de que o material para começar uma oficina de arte foi obtido por meio de uma rifa de uma toalha de mesa do enxoval de uma das professoras... Deixo esta informação como mais um aspecto para se refletir.

\section{Referências Bibliográficas}

ALBUQUERQUE, C. et al. O Ensino de Educação Artística na Grande Florianópolis. Universidade e Desenvolvimento. Florianópolis: UDESC, (1), 1993, p.42-52

BARBOSA, A. M. Arte-Educação: Conflitos/Acertos. São Paulo: Max Limonad, 1984.

LANIER, V. Devolvendo a Arte à Arte-Educação. AR'TE, São Paulo, v.10, n. 3, 1984.

OSTROWER, F. Criatividade e Processos de Criação. Petrópolis: Vozes, 1983.

PLAZA, J. Tradução Intersemiótica. São Paulo: Perspectiva, 1987.

PORCHER, L. (Org.). Educação Artística: luxo ou necessidade. São Paulo: Summus, 1982. Trad. de Yan Michalski.

RAMALHO E OLIVEIRA, S. R. Fenomenologia da Experiência Estética: uma alternativa na preparação de educadores. Dissertação (Mestrado em Educação) - Programa de Pós-Graduação em Educação, UFRGS, Porto Alegre, 1986. 
Ramalho e Oliveira, S. R. et al. O Empirismo Metodológico no Cotidiano do Professor de Educação Artística. In: III JORNADA DE PESQUISA DA UDESC, 1998, Florianópolis. Anais... Florianópolis, 1998.

Ramalho e Oliveira, S. R. et al. O Empirismo Metodológico na Prática do Professor de Educação Artística. Relatório PROBIC/CNPq/UDESC. Florianópolis, 1994.

VYGOTSKY, L. S. A Formação Social da Mente: o desenvolvimento dos processos superiores. São Paulo: Martins Fontes, 1991. Trad. de José Cipolla Neto, Luis S. Menna Barreto e Solange C. Afeche. 